\title{
THE EDITING OF FRENCH TEXTS FOR SCHOOLS AND COLLEGES
}

The chief purposes of this article are (I) to characterize certain typical English and American editions of French texts usually designated as Elementary, Intermediate, or Advanced, and intended for schools or colleges, (2) to restate or to formulate standards by which such books may be fairly tested, (3) to offer by the way certain constructive suggestions.

If my principal statements are accepted as correct, one of the conclusions to be drawn may resemble that which a 'live' manufacturer usually draws when someone can prove to him that his machinery does not work fast enough, whatever it produces, or that it produces an inferior article.

My facts are derived from complete examinations of a score, at least, of English or American editions (mostly the latter) published during the last twenty years or more, and from the perusal of many others, with approximately the same results from merely glimpsing as from careful scrutiny.

My conclusions are based not only upon these facts, as I conceive them, but upon several assumptions: One assumption is that the chief motive in studying French should be to learn as much French as possible (rather, for example, than to enrich one's mind with 'general ideas,' or to discover whether it is Armand or Daniel who finally carries off the daughter of M. Perrichon); another assumption is that being a living language, French should be taught as such; another is that the best work that the most competent editor can do is well devoted when he edits a text for his juniors (a rare occurrence; but maxima debetur reverentia pueris virginibusque); a kind of corollary to this is that young students, especially, should not be encouraged to slovenly ignorance by the use of slovenly textbooks (an obvious maxim and a common practice), nor should students of any age be instructed with bad or good examples of bad methods. What methods I venture to stigmatize as bad will be stated in the following paragraphs.

The features to be considered are ( $\mathrm{I}$ ) the reprinting of French texts, and (2) the notes, vocabularies, etc. that usually follow them; as for the introductions with which the majority of such 
texts are supplied, they suggest to me no remark except that in each and every one I should like to see the reader reminded, if need be in italics, that a full appreciation of the beauties of literature is possible only to those who understand accurately the language in which that literature is written and who know furthermore how to pronounce that language, or how it sounds when correctly pronounced; that the language is therefore the primary object to be studied; but I will reserve my observations on this point to the section on Notes.

THE REPRINTING OF THE FRENCH TEXT

1. The great publishing houses do their part so well that their reprints not only have a French physiognomy but are often better printed than their sources. For textual mistakes it is usually the editor who is responsible, for it is he who provides the 'copy,' and he has ample opportunities to correct all misprints.

2. In the first place, the editor usually neglects to state precisely what edition was his immediate source. Also he sometimes garbles his original by introducing, altering, or omitting chapterheadings, and commonly fails to say whether he has altered the text proper.

When the editor cannot reprint a text in its entirety, every omission should be indicated by $* * *$, by [***], or otherwise, but unmistakably, and in his preface he should say precisely what he has omitted and why he omitted it. Here is an annotated edition of Gil Blas from which many passages have been silently struck out, while chapter-numbers have been changed to suit the editor's version. He has garbled Gil Blas; whether so as to make any passage obscure, I do not know; but such is the result in the case of an edition of Salammbo (in a 'Higher French Series'), for here the silent omission of somewhat more than two pages (p. 6I), belonging to Flaubert's description of the temple of Sanit and its occupants, is essential to an allusion (p. 64) to those occupants and to certain features of the ornaments of the temple; Flaubert suffers, and the reader, if intelligent, must become confused. No note. But the editor should have epitomised the omitted passage, enclosing in [] whatever he has inserted. Since teachers almost never have the time to collate, and frequently lack the 
means, they are commonly at the mercy of the editor and may be seriously embarrassed by students' enquiries as to such obscurities.

A philological training would be of great value to all such editors, and perhaps the time is near when such training will be made obligatory for all teachers above a certain grade. ${ }^{1}$

\section{II}

\section{NOTES}

1. What are the most constant characteristics of the Notes usually included with the French or other foreign texts chosen for our classrooms, and what kinds of notes are worth most?

A careful inventory of, say, twenty annotated editions, taken at random from the hundred and fifty or more in almost any favored teacher's stock, would offer pretty definite statistics, simplified by marked uniformity of methods in editing.

2. The non-linguistic notes usually deal with facts or with supposed facts which the student, and often the teacher, must learn if they are to understand the social background of the text, the complications of its plot (if it has one), and endless other matters that might be equally valuable to someone wholly unacquainted with the original text. Even the most learned reader needs such notes; for though it may be true, not everyone is aware that, for example, 'the social position of the mercantile class in France had greatly advanced under Louis Philippe (I830-1848)', nor suspect that 'Frenchmen have always maintained that women have a separate and different "sphere" from that of men'; it may even be worth somebody's while to note that 'Eugenie [Grandet] here and elsewhere displays a charming naïvete.' Usually such notes, however unequal in their interest or their relevance, save time which can be devoted to more careful study of the author's language, and they may even reveal genuine research. Here,

'By 'philology' I mean the systematic, thorough, and, in so far as may be, the objective study of language, or of a language, in all its aspects, whether it happens to express 'literature' or not. Since literature is an aspect of language, philology, as here defined, includes the study and editing of literary works, in the interest of truth. There is little truth and no profit in the common opinion that philology is the occupation of a few unimaginative persons whose principal interest exhausts itself in studying the origin of words. Fortunately for the public, all the physical sciences (including medicine and surgery), require more exact and more exacting methods than those which are generally followed in studying literature; however, in the literary field mistakes are seldom fatal. 
for example, is the musical notation of an air mentioned in Eugenie Grandet, or possibly the editor has taken the pains to insert a correct map of the scene of his story, when that scene is not fictitious. The more he can do toward producing a French atmosphere, the more his readers will owe him.

3. In most annotated editions, non-linguistic notes are mingled with linguistic notes. What advantage arises from printing them in separate sections? - the apparently novel plan adopted in the Eugenie Grandet just mentioned (a model edition, in so far as its non-linguistic notes are concerned).

A student who consults notes knows approximately where to open his book; but, since he is expected to look up every difficulty as it arises, and this seems to be his most reasonable course, such a division sends him from one line to a linguistic note, from the next to the non-linguistic section. Thus he possibly spends a few more seconds looking than if there were no such classification, but possibly he profits by developing his sense of order. As for the more inquisitive critic, he sees at once what relative importance the editor attaches to his two different kinds of comments.

To his non-linguistic notes Prof. *** devotes 24 pages; to his linguistic section (called 'Grammatical Notes'), an appendix of 8 pages in which he has classified a few of the syntactical phenomena illustrated in Eugenie Grandet. How can the teacher use such a diminutive treatise? And how and when is the student expected to use it? The treatise refers to numerous places in the text, but the text contains no reference to the treatise; but how in any case can such a synthesis be as tuseful to student or teacher as a presentation in which important or merely difficult ' grammati$\mathrm{cal}^{\prime 2}$ phenomena are noted or explained upon their first appearance? If synthesis is desirable it can be adequately attended to by an index.

4. In every French text, difficulties abound, and considering how few teachers are keenly and intelligently interested in the very aspect of the French, or other foreign text, which for both teacher and student should be its most important aspect (See $\S 5$ )the student is supposedly endeavoring to become acquainted

\footnotetext{
${ }^{2}$ Furthermore, why, here or elsewhere, should students be tempted to perpetuate the archaic notion that 'grammar' is limited to syntax, with a little morphology in the shape of conjugations, etc.? Why not try to impress upon them what all the great modern grammarians mean by 'grammar'?
} 
with French-, should not its linguistic aspect be made to dominate? Further, to return to an enquiry already made, if 'grammatical' notes are thus isolated, and synthesized, and not referred to in the text itself, the only time when the student can consult them with any profit, and that profit will be small, is after he has read the whole text, or most of it; for even though the teacher may be willing to make his own index from the text to the treatise, and even though this treatise be adequate, the student must come to class to get the information which should have been at his disposal while he was preparing his lesson. Furthermore, if consistency is worth something, why should not the non-linguistic notes be classified in like fashion?-they could be classified, quite as surely as grammatical or lexicological facts can be classified.

5. In at least ninety per cent. of the editions now under discussion, an overwhelming majority of the linguistic notes are merely translations of words or locutions ('idioms'), thus either usurping a function which belongs to the Vocabulary (chap. III) or repeating many of its definitions; further, the editor thus gives a personally expressed result, merely one result, for a given word or locution, instead of an explanation from which the student might learn simultaneously some principle of grammar or lexicology, being free then to offer his own interpretation, this to be corrected by his teacher if it is wrong or clumsily expressed. Authors of mathematical textbooks almost never solve for the pupil the problems that they have set for him. Why should our editors do so? Why not force the student to strengthen his brain by actually using it? Why teach languages on a lower plane than mathematics or the physical sciences? Save in those few cases where the explanation might have to be unduly subtle or quite too long, the substitution of translations for explanations seems to me a fundamental error in method. An explanation of faire l'important would or should enable even a rather dull student to understand faire le soldat; merely to translate it (for example, with 'to be so stuck up') teaches little or nothing to the average undergraduate; if work is done for him, of course he will not do it for himself, and the more numerous such translations are the more will he be inclined to accept and perpetuate the common delusion that 'French is an easy subject'-a statement which we have read or heard scores of times, though our acquaintance 
may include not more than ten American college graduates who can be said to speak and write French correctly-the convincing proof of knowledge when a living language is concerned, of two kinds of knowledge, for, to speak correctly, complete control of the vocal organs m'sst have been acquired. French may be easier than Latin for those who treat both as dead languages.

Consider another example: avoir beau + infinitive, capable of numerous meanings, often totally dissimilar in their English forms, requires explanation, or, at least, a reference to some well-known grammar wherein it happens to be intelligently explained; but here arises a 'practical' difficulty, for the editor's publisher may be unwilling to mention other publishers' textbooks, or many thousands of students may never have heard of the grammar referred to. That is one very good reason why the editor should deal, as fully as his knowledge and his publisher allow, with all the difficulties that reasonably industrious students are likely to see (or to miss!) in a given text; another good reason for doing this is that extremely few school-children or undergraduates of either sex ever look up a reference; finally, it is at least conceivable that the teacher herself (in the schools of the United States, seldom himself) will not be able to explain the difficulty.

There are other good reasons why grammatical or purely lexicological facts should be explained adequately and constantly-if possible.

I. The student should never be allowed to forget that what he is primarily attempting to learn is the French language. If the texts that he uses are well chosen, his appreciation of French literature (inseparable from the medium in which it is expressed) will develop almost unaided; but one cannot become a botanist or a gardener by merely loving flowers, and usually it is those persons who know most about them who love them best. Similarly, the beauty of a linguistic construction, its fitness, should be most apparent to him who understands it best, and if he does not understand it, the chances of his being able to employ it correctly are lessened.

2. In so far as it may be analyzed at all, 'style', it seems to me, is almost wholly a matter of sounds (How do they occur?), of syntax, and of what may be called the tone or standing of a word or locution (Is it vulgar, or colloquial yet nicely used? Is it 
living, or purely bookish, or otherwise archaic? Is it apt, or merely affected? Is it technical, or rare, or dialectal, or characteristic of its user, or in everyday use? Etc., etc.) Possibly the teacher may often be able to answer such questions; often neither he nor the books that he knows can do so, and in any case the student should be kept aware that such questions are worth while.

3. Is it some pedagogical theory that has caused an overwhelming majority of the annotators of French texts to devote to non-linguistic matters an overwhelming majority of the notes that are not mere translations? In my opinion, the explanation is that the overwhelming majority of such editors are not deeply interested in the linguistic aspect, and this surmise seems to be substantiated by the fact that nearly all the dissertations and nearly all the maturer writings of most of our teachers of French arewhat shall we call them? is not 'non-linguistic' correct? And is this condition not due, in its turn, largely to the fact that our environment does not help us to speak French, but rather hinders our doing so, with the natural consequence that most of us have to find our French purely or largely in books? In the schools of Scandinavia and Germany, of Holland and Belgium, a good many students learn even how to speak French, at least passably; perhaps that result would be far more difficult to attain in this country, but it is worth an effort, and such an effort would be greatly helped by making our editions of French texts primarily instruments for learning the French language.

III

\section{VOCABULARIES}

1. Believing that French and other modern language texts 'sell better' if provided with a vocabulary, most publishers expect, and often ask for this feature, and they commonly recommend that it should be 'very full' or 'complete'.

Under this pressure, if not because he thinks best to add one anyhow, the editor usually compiles a vocabulary, or, for reasons which it would often be interesting to know, he entrusts this task to $\mathrm{X}$. If he is convinced that $\mathrm{X}$ can do the work as well as himself, or well enough, or better, and $X$ is willing, so much the better, possibly even for the public; but even narrow-gauge lexicography demands several rare qualities, unless it is to be of the sort that we generally let pass. 
2. What qualities would make such vocabularies good? And when they are good, what is the justification for making them?

In the first place, to be good, need such a vocabulary be complete? In the case of very short texts, such a degree of completeness as would enable an absolute beginner to understand every phrase (at all events if helped by occasional notes) is easily attainable; but even with brevity aiding, omissions are frequent, and an increasing length of text means a fast-increasing risk of omissions and of errors. Many of the longer vocabularies, especially, give the impression that after making a list of most of the individual words their compilers must have translated those words without regard for the text, hit or miss, giving the English equivalents which one might find in a pocket-dictionary of the Feller type, so that the puzzled reviewer has often to conclude that such and such a tail cannot belong to such and such a cat; the student fares worse.

3. That most such vocabularies are intended to be 'complete,' and that they may safely be appraised as so intended, is to be assumed from the presence of beau, frère, ici, and the like, in editions called Intermediate, or Advanced, when no special locution is involved; but even a cursory examination, or a few days' experience in the classroom, will suffice to prove that no such vocabulary is literally 'complete,' that most of them are far from being so, and the omission of many locutions which cannot be defined if their component parts are scattered is particularly notable. If we grant that completeness is possible, or a close approach to it, when, if ever, is it worth while?

Save perhaps commercially, it is certainly not worth while for the compiler unless he does his work beautifully, in which case he may give himself a lesson in lexicography, that lesson being greatly simplified by the fact that nothing in his text, if modern, is likely to require long investigation.

Is a complete vocabulary worth while for the teacher who uses the book? Certainly not, unless it tells him what he cannot easily learn elsewhere; but this is almost never the case, nor, as a rule, does he discover that the compiler has taken particular pains to use idiomatic English. A set of complete (accurate) vocabularies for several works of a given author, as Labiche, would of course throw light on his usage, might contain material valuable for comparative studies, etc.; but is it likely that this comprehensive task will ever 
be undertaken? And how many of the special vocabularies now existing in the backs of elementary textbooks (their true character) would be found worthy bases or adequate contributions? Probably none, and certainly none of those in which à is defined as meaning 'at, by, for, in, till, to, with,' or the like. Furthermore, the scientific value is nil unless exact references are given for all examples.

Of what value are such vocabularies to the pupil? I suppose this to be the point most worth considering.

Obviously, even though not really complete, they save time for him. But why should time be thus saved for him if, after a year or more of study, he still has to look up words such as absence, aimer, auquel, autre, car, ceci, etc.? Would such ignorance be too severely penalized if the student of this type found himself compelled to consult an ordinary dictionary, the dictionary which he should be expected to own and to use in any case?

That every word and every mysterious combination (e. g. avoir beau + infinitive) should be dealt with for very young pupils, even père and mère, is perhaps desirable; but this depends upon what kind of 'French for Beginners' or other introductory lessons this pupil can be assumed to have had, and in all cases, it seems to me, weaning should be begun as soon as possible. To include any simple word that the student must have met dozens of times is a practice that should be discontinued; in my opinion, no word or locution should be included if the pupil has already encountered it frequently, or if it can be readily found, clearly defined, in any of the six or seven French-English dictionaries (nearly all containing the same matter) now used in our schools. The editor must know what is unquestionably to be included or excluded. If, for example, in lui prenant la main, the pronoun has a value peculiar to French, and therefore inconvenient to define, the editor may be justified in explaining that value in his Notes; the chances are that he has recorded je but forgotten lui, just as the chances are that he has recorded aller but has omitted irai and vont, or has put them only under aller, where students as ignorant as many of his insertions imply would often not think of looking.

3. As has been pointed out (chap. II, $\S 5$ ), in an overwhelming majority of the editions under discussion, when the notes are linguistic they consist mostly of translations, many of which should 
be replaced by explanations, while a still larger number duplicate the alphabetical vocabulary or usurp its functions. Thus, to return to 'a terrible example' of bad workmanship by an editor de cuyo nombre no quiero acordarme, in a certain edition of Perrichon we find the following: (note) 'bouscules, lit. "jostle" here worry'; (vocab.) 'bousculer, jostle, worry';--(note) 'en nage, dripping with perspiration'-nothing as to the 'literal' meaning of nage; the vocabulary has 'nage, $f$., en nage-, dripping, perspiring'. Etc., etc. Sheer waste, and even worse; for this sort of thing helps to engrain indifference to that neatness of workmanship which is one of the chief ideals of good scholarship, a lesson that every student should learn and a method of procedure which in almost any textbook in mathematics or other subjects wherein verbosity is not traditional and accuracy is the main and everpresent ideal, would less often be regarded as venial. In such textbooks, accuracy of statement and neatness of workmanship are habitual and are taken for granted, or the exceptional specimen is soon discredited; many of the worst annotated editions of French texts continue to be used (sometimes by hundreds of students) fifteen or more years after publication, and such editions are often abandoned, not because they are bad, but because some other French text is desired by teachers; they cannot be blamed for getting tired of texts that they have used repeatedly, even though a few of these happen to have been well edited.

4. It is seldom difficult to decide whether a given word or group requires definition rather than comment, but each of these requires philological competence, and accuracy of definition (this markedly concerns locutions) demands a sense of linguistic values, a genuine fondness for the right shade of the right color, a very keen understanding of French and a rich sense of English idiom. Bad English never correctly translates good French. Therefore, if the editor happens to be so gifted, he can render a service not generally rendered; he can constantly remind the student of the differences between the two languages, explaining in what they consist, and he can do this generally to better advantage than the teacher, for the teacher has seldom made a special study of the text in question; so the editor's definitions may be justified in his notes. 
5. There are many things with which no vocabulary can deal adequately-among them, the values of tenses. Take, for example, the group of verb-forms exemplified by il écrivait. No vocabulary can easily display the various possible English meanings (or semantic functions) of such a form, and as our undergraduates make a particularly bad showirig in this matter (for the most intelligent among them appear to have heard vague things about it), the editor can clarify without infringing the teacher's rights; before the student goes to 'recite' the editor can at least give him a chance to decide whether écrivait, or whatever the verb and form happen to be, means 'wrote', 'was writing', 'could write', 'used to write', 'would write', or 'kept writing', etc. As 'wrote' is the habitual translation or mistranslation, even of the best students, this experiment, and others, might well be stated early in the notes, and constantly referred to; the lesson in English is purely incidental, incidental but indispensable.

6. To summarize and conclude sections $I-5$, it seems to me that the editor should state why he has given to his vocabulary whatever character and purpose he supposes it to have; it seems to me that if he has included 'beau, beautiful' and 'oncle, uncle' in a list not intended for infants, he should at least try to shift the blame to those for whom he has thus sinned, that he should not Fellerise his text, that he should not duplicate anything, and that he should distinguish between commentation and lexicography. If there were any likelihood that such a resolution would be respected by all editors of French texts, the passage by some recognized body of the following resolution might be salutary:

WhEREAS all but the most backward students should be expected, after a year or two of uninterrupted study, to know the meanings of all words and locutions which they have met scores of times in their readings, and wHEREAs for such students the frequent consultation of a general dictionary is in any case a desirable feature of their linguistic training; wHEREAs, furthermore, even approximately 'complete' vocabularies are not only of dubious scientific value when attached to ordinary textbooks, but also waste the time of their compilers, tempt them to be inaccurate, and require space which should be devoted to less accessible knowledge, be it resolved that in the case of so-called Intermediate and Advanced texts intended for use in our schools, colleges, or universities, the addition of a 'complete' or ostensibly complete vocabulary is undesirable, and that if any vocabulary is to be added it should 
be strictly relevant, containing only such words or locutions as students of a given grade may reasonably have forgotten, or (preferably) such as they may be assumed never to have encountered or might not easily discover, adequately defined, in any of the several dictionaries recommended to students for their preparatory or undergraduate work in French, Spanish, Italian, German, and other living languages commonly taught in our schools and colleges. Be it resolved, furthermore, that copies of this Resolution be sent to all members of this Association, and that it be brought to the attention of those publishers who make a business of publishing scholastic editions of foreign texts intended for linguistic study.

7. Should the pronunciation of such French words as are included in the vocabulary be indicated?

If the publisher can supply the right typographical characters (preferably those approved by the International Phonetic Association), yes; but the editor should not use any system not generally recognized, no matter how 'scientific,' should not use any bad system (e. g. one in which jour is represented by 'zhoor'-this is authentic), and his work would probably be most useful if he followed the system of the International Phonetic Association. Under no circumstances should he neglect to indicate the pronunciation of words or of groups of words which even very good teachers might otherwise not know how to pronounce-for example, the plural of arc-en-ciel. None of the present phonetic dictionaries are complete; their omissions are numerous and sometimes embarrassing.

8. Genders are strikingly well indicated in a very recent edition of Le blé qui lève.

IV

QUESTIONNAIRES AND EXERCISES FOR COMPOSITION

1. Whenever a text happens to contain a large proportion of colloquial living French, what better material could the student have for queries to be answered in sentences based on that colloquial element, or for written work? But it is obvious that such material should be exploited in either case with the most scrupulous care not to ask what it does not explain, except in so far as the teacher can rely on knowledge already acquired.

2. As for Questionnaires, an edition of Le cousin Pons exemplifies admirably both what should, and what plainly should not 
be asked of any known American undergraduate. Here are some inquiries which might produce intelligent and intelligible responses: [I] 'Quel âge avait l'homme?' [2] 'Cette raideur pourquoi n'excitait-elle pas le rire?' [3] 'Duquel des péchés capitaux était-il esclave?' [4] 'Pourquoi tous ses anciens amis l'abandonnaient-ils?' Likewise a good many other questions allowing a response taken word-for-word from Balzac's story; but the editor devotes a third as many questions to his own English 'Introduction', in which, of course, the vocabulary is largely not colloquial (for the most part, highly 'bookish'), and here are some of the questions he asks about it: [I] 'Quelle est sa vie après sa faillite?' [2] 'Décrivez ce qu'on appelle "sa vision prophétique"!' [3] 'Comment expliquez-vous la prépondérance du physiologique dans son oeuvre?'-i. e. cuvre. [4] 'Qu'est-ce que c'est que "La Comédie Humaine?" ' [5] 'Décrivez un peu la société de son temps!' And on 'Characters': [6] 'Que dit M. Harper? La Revue d'Edinbourgh [sic]? Poitou? Caro? Stevens? [Leslie Stephen] James? Parsons?' For whom was all this and more intended?

3. The principle stated in section I seems to cover adequately appendices devoted to Exercises in Composition; however, I shall venture to enlarge upon it, deriving my illustrations from an edition of Perrichon (not the edition previously mentioned).

The four acts yield this editor thirty-one exercises, of which two at a time would be a reasonable assignment for a fifty-minute 'recitation'. His sentences are mostly short, have a pleasingly natural tone of continuity, are almost never strictly 'bookish', are nearly all properly based on the French text, yet force the student to use his 'head' as well as his eyes, and afford the teacher many chances to slip a little mirth into his instruction as he passes along the blackboards, correcting, or commenting.

The defects of these particular exercises, and of many others having the same intention (to utilize for oral or written work in French the text preceding them) are worth noting because they are general:

I. The editor has used a few expressions which are not justified by Labiche's text (certainly not by the parts to which the student is referred), expressions which even a very good student would be unlikely to have in his general stock and would probably be unable to find in his dictionary. For example: 'thank your lucky stars,' 
'who is running off with my valise' [italics mine], 'with a commission in the militia,' 'the whole family drove back' [italics mine], 'do not always harp on the same string', etc.

2. His English is not always truly colloquial, as it should be wherever it corresponds to truly colloquial French (most of Perrichon is truly colloquial). For example: 'The road you are following is not the highway, but I think you will succeed none the less for that' [italics mine; note also a certain looseness of connection]. A few groups such as 'let us', 'do not', 'it is', and the like, should be 'let's', don't', 'it's', etc., for spoken English distinguishes between the shortened and full forms, and its distinctions should be noted in all attempts to reproduce conversation in print. In general, this editor is extremely careful on such points; other editors seem wholly unaware of the importance of distinguishing between truly colloquial English, or French, and clearly bookish English, or French.

3. In one or two cases his English is not English. For example: 'When strikes the hour for the duel. . . .

4. His footnotes neglect scores of difficult expressions (mostly at least indicated by the text, or to be found in general dictionaries), yet they translate words such as 'true' (with vrai), 'like' (with comme), 'yet' (with pourtant), 'money' (with argent), 'often (with souvent), 'several' (with plusieurs), etc., etc., all these examples being quoted from a single page.

Such footnotes are so strikingly superfluous that their presence is difficult to explain. May it be attributed to the influence of that traditional lack of systematic care which is apparent in so many modern-language textbooks, to a greater or less degree in nearly all? It seems to me that every detail should be scrupulously considered before any such book is printed; for a large part of this kind of work the editor need not have passed through any philological school to have acquired the nccessary skill, valuable though such a training is in most of the phases of editing, even in the editing of texts chosen because they are fitted for the elementary work of our schools and colleges. But for this purpose an editor must have at least one quality which is not required of a Suchier or a Gaston Paris: he must know how to make the best work that he can do clear and attractive to young and old simultaneously, whether their grade is 'elementary, 'intermediate,' or 'advanced.' 


\section{CONCLUSION}

Whether or not a very large proportion of the kinds of editions which we have been considering deserve the fate which befell Don Quixote's libros de caballerias, they all might well be subjected to a scrutiny having something of the same character and intention. Accuracy in details should not be regarded as excusing manifestly bad methods. Good methods are known to those persons who have taken the pains to ascertain them, and there is no reason why they should not become more general, nor why the tests of excellence (or of the contrary) upon which they rest, or which they imply and apply, should not be used widely and be transmitted by teachers to all the pupils who can understand them. They are not difficult to understand.

The University of Chicago.

RICHARD T. HOLBROOK. 